\title{
Uma "Tempestade" Chamada Latour: a Antropologia da Ciência em Perspectiva ${ }^{1}$
}

SÉRGIO CARRARA ${ }^{2}$

Há alguns anos, as livrarias brasileiras acolheram a tradução do livro Nous n'avons jamais été modernes - essai d'anthropologie symètrique, do antropólogo francês Bruno Latour. Não era sem tempo, pois, construída entre San Diego e Paris, a obra de Latour $^{3}$ é já extensa, vem causando polêmica e tem-se mostrado extremamente influente, sobretudo entre aqueles de nós que têm como "tribo" a comunidade científica e sua produção. É uma pena que sua estréia aqui tenha sido feita através de um trabalho eminentemente teórico e de assumido caráter ensaístico.

Para os que não conhecem as etnografias que o precederam e prepararam (Latour, 1978, 1984, 1989), ele certamente pode parecer um tanto hermético, abstrato ou "fillosófico". Porém, mesmo que não se tenha uma idéia exata de todas as implicações práticas das proposições contidas nesse livro, talvez muitos que o leram compartilhem da estranha sensação de estar diante de uma dessas catástrofes anunciadas, já tão costumeiras no Brasil. Como uma tempestade de verão, o pensamento de Latour parece ser ao mesmo tempo esperado e temível, previsível e surpreendente.

Se o ensaio de Latour tem algo de esperado e previsível, talvez seja pelo fato de que, nele, a trajetória apenas esboçada pela antropologia social ao abandonar o mundo "primitivo" atinja seu limite. À primeira vista, as imagináveis conseqüências da conclusão de Clifford Geertz, de que "agora somos todos nativos" (Geertz, 1983), nunca tinham se concretizado de modo tão radical, ou ao menos de forma tão radicalmente sedutora.

De outro lado, as idéias de Latour são temíveis e surpreendentes, porque procuram desvelar e subverter radicalmente nossa percepção do mundo, quer nos definamos como modernos, antimodernos ou pós-modernos; relativistas ou etnocêntricos; realistas ou construtivistas; adeptos da idéia da história como processo contínuo ou como uma série de revoluçōes políticas e epistemológicas.

Muitos podem achar isso improvável. Tantas vezes, nos últimos 20 anos, sentiram o "solo" se mover abruptamente sob os pés, abalando seus mais caros valores, suas mais sólidas certezas. Porém, para os que achavam 
impossível haver novas revoluções, para os que já aceitavam o fím da história, preparando-se para pagar com a desesperança o preço do ingresso a uma eternidade "where nothing ever happens", eis Latour!

Latour parte do princípio de que "nossa vida intelectual está muito mal feita" (Latour, 1991, p. 13). Uma série de separações violentamente arbitrárias estaria nos impedindo de aceder a uma compreensão mais acurada do mundo à nossa volta. Para ele, a mais superficial leitura de um jornal diário é suficiente para revelar que estamos cercados por entes que já não conseguimos mais classificar facilmente. Tomemos as notícias sobre AIDS, diria Latour, e nos preparemos para enfrentar nada menos que os macacos verdes, os sofisticados laboratórios franceses e americanos, a decadência do mundo ocidental, os haitianos pobres, os virologistas, os governos do Primeiro e do Terceiro Mundo, as lúgubres florestas africanas, os ricos homossexuais nova-iorquinos, os deuses em cólera, as diferentes culturas sexuais, a imprensa, o Papa, a ONU, os doentes organizados, a indústria farmacêutica, os militantes gays e antigays, certos vírus infinitamente pequenos e traiçoeiros, os antropólogos, os cientistas sociais e - por que não? - o futuro da espécie humana.

No entanto, segundo Latour, ao analisar fenômenos como a AIDS (ou qualquer um dos outros que listamos como estando a ela relacionados), tendemos ou a considerá-los fatos naturais e objetivos, como fazem em geral médicos, biólogos, virologistas etc., ou a vê-los (geralmente contra aqueles) como fatos sociais, culturais ou discursivos, dependendo da nossa filiação teórica. Ou são coisa, ou são representação; objeto ou sujeito; fato ou símbolo; matéria ou idéia. Só não podem ser as duas coisas ao mesmo tempo. E, no entanto, para Latour, elas o são "de fato", mesmo que não "de direito". São, como diz, ao mesmo tempo "reais como a natureza, narradas como o discurso e coletivas como a sociedade" (Latour, 1991, p. 15). E é nesse "direito", nessa espécie de constituição que nega "cidadania" a tais híbridos, a tais "quase-coisas" ou "quase-sujeitos", que Latour vai localizar as dificuldades que temos em abordá-los.

Para Latour, somos governados por uma constituição moderna, cujos articuladores míticos teriam sido Hobbes e Boyle. Contemporâneos, eles teriam lançado, em pleno século XVII, a pedra fundamental dessa espécie de Muralha da China que, desde então, teria passado a separar o reino das "coisas-em-si" (a natureza e os objetos) do reino dos "homens-entre-si" (a sociedade, a cultura, o sujeito), expulsando para sempre Deus dos negócios desse mundo e enclausurando-o no coração de cada um. 
Entretanto, como um rito de passagem, essa constituição distingue não só os estados por ela separados (nosso presente moderno e nosso passado pré ou não-moderno), mas também abre um abismo intransponível entre os que um dia se submeteram ou se submeterão ao rito e os que não o fizeram e jamais o farão (Bourdieu, 1982).

Assim, segundo Latour, no momento em que a constituição moderna é "outorgada" ou "promulgada" (ele não esclarece exatamente como se deu o processo de implantação), ela passa a operar uma nova, injusta, artificial e discutível separação, interpondo um oceano entre a modernidade européia e o mundo "primitivo", onde todas as metamorfoses, todas as confusões, todas as misturas e trocas permanecem possíveis e permitidas. Grand partage exterior que, para Latour, não é senão a outra face desse grand partage interior. Logo, no momento em que os modernos separaram "palavras" e "coisas", instituíram, como seu "outro" irredutível e necessário, aqueles que não o fazem.

Para Latour, as tentativas feitas até hoje para superar esse abismo entre homens e coisas, Oriente e Ocidente, primitivos e civilizados, fracassaram, acabando por aprofundar ainda mais a separação contra a qual aparentemente se insurgiram. Fracassaram porque foram reducionistas e assimétricas. Criticou-se o naturalismo, sem que fossem igualmente criticados seus irmãos siameses: o culturalismo e o sociologismo. Denunciou-se o caráter nãonatural da natureza, sem que se apontasse para o caráter não-social da sociedade, cada vez mais povoada de coisas, de híbridos. A radicalidade de Latour está em voltar assim as armas da crítica contra ela própria (afinal, quem haveria de criticar os críticos?), denunciando sua parcialidade e totalitarismo.

A inovação de Latour parece residir justamente no fato de mostrar que, embora aparentemente em posições opostas, tanto realistas quanto construtivistas (quer sejam modernos ou pós-modernos) estiveram regidos por uma mesma constituição moderna, que eles lutaram para preservar. Em suas análises, estiveram igualmente empenhados em um mesmo trabalho de "purificação", reduzindo os inaceitáveis híbridos, quer ao pólo natureza, quer ao pólo sociedade.

E no entanto, conforme defende Latour, a antropologia social sempre soube muito bem como abordar essas culturas-naturezas (como prefere denominar o que chamaríamos de culturas ou de sociedades), quando abordava os não-modernos, os ágrafos, os sem-Estado. Como diz Latour, 
“(..) mesmo o mais racionalista dos etnógrafos, uma vez enviado para longe, é plenamente capaz de relacionar em uma mesma monografia os mitos, as etnociências, as genealogias, as formas políticas, as técnicas, as religiões e os ritos do povo que ele estuda (...)" (Latour, 1991, p. 137).

Talvez tenha apenas faltado dizer mais explicitamente (de fato, não sabemos se o autor já o disse em outro momento) que, se os etnólogos souberam muito bem tratar essas misturas, foi porque, em sua maioria, embeveceram-se com os trabalhos de Claude Lévi-Strauss (para Latour, um dos campeões do grand partage) ou não puderam escapar à magia de dois textos seminais para a disciplina e que, sem que Latour o assuma, estão na base de suas idéias. Referimo-nos ao Esboço de uma teoria geral da magia e ao Ensaio sobre a dádiva, ambos de Marcel Mauss (Mauss, 1991 [1902-3] e 1991 [1923-24]).

Em ambos, Mauss tematiza justamente essa mistura das almas nas coisas e das coisas nas almas que caracterizaria toda a vida social e, no Esboço..., estabelece firmemente o caráter híbrido da magia, posicionada entre a ciência e a religião. É certo que Mauss enfatizava sobretudo a dimensão técnica da magia, que estaria assim muito menos voltada para o estrídulo "comércio" com os deuses do que para o mais discreto e balbuciante "comércio" com as coisas, que, a seu modo, a ciência continuaria.

Porém, diferentemente de Latour, para Mauss (como aliás também para o seu tio $^{4}$ ), a mistura incessante de coisas e idéias, promovida, quer pela magia quer pela ciência, não jogaria os homens em um universo povoado de híbridos aleatórios. Ou seja, não seria qualquer mistura que estaria fadada a perdurar. Para ele, a atividade científica é intrinsecamente técnica (estritamente simbólica, diríamos) e, nesse sentindo, transcendente ${ }^{5}$.

E seria justamente essa transcendência a condição da sua eficácia. Como diria Mauss em um texto posterior, através da técnica, mágica ou científica, o homem se mistura às coisas, as transcende e transcende a si mesmo:

"Ele se identifica à ordem mecânica, física e química das coisas. Ele cria $\mathrm{e}$ ao mesmo tempo cria-se a si próprio, cria seus meios de vida, coisas puramente humanas, e seu pensamento inscrito nessas coisas" (Mauss, 1969[1927], p. 197).

O que defende Latour? Que a antropologia seja simétrica. Que continue fazendo o que sempre fez e do modo como o fez, mas agora com os "mágicos modernos", os cientistas, entre os quais os antropólogos, devem 
necessariamente se incluir, aceitando ver ser tratados como tantas outras "categorias nativas" seus próprios conceitos. Devem mostrar aqui também como a ciência continua vinculada tanto à técnica e às coisas quanto à religião e aos deuses, ao parentesco, à política, à economia, à culinária etc. Não são apenas fatos sociais totais, são fatos totais. Obviamente, entre nós, essa análise deve se desenvolver lá onde a prática de hibridação ocorre - ou seja, no laboratório, entre cientistas e técnicos. Sem dúvida, trata-se de um ultra-empiricismo.

Para Latour, a realidade empírica abarca somente os híbridos ou quasecoisas, as práticas que os produzem, as que os escondem e as redes mais ou menos extensas que os ligam aos homens. É das coisas e das práticas que o antropólogo deve partir para, somente ao final de seu trabalho, perceber como elas produzem e reificam, de um lado, uma determinada sociedade, cultura ou sujeito e, de outro, uma determinada natureza, realidade ou objeto. Só desse modo, diz ele, poderemos compreender "um mundo no qual a representaçăo das coisas por meio do laboratório nunca está dissociada da representação dos cidadãos por meio do contrato social" (Latour, 1991, p. 43).

Para Latour, portanto, nós nunca fomos modernos e conseqüentemente não poderíamos ser pós-modernos. De fato, diz ele, nós nunca deixamos a velha matriz antropológica. Nossas sociedades operam exatamente como todas as outras que aprendemos a chamar de "primitivas", salvo pelo fato de que aqui a constituição moderna vigente nos tem vedado até o momento uma abordagem objetiva dos híbridos que dela fazem parte, tal como os homens. Mais que isso, para Latour, essa proibiçăo teria mesmo propiciado a produção de tais híbridos em uma escala sem paralelo. Para ele, a Muralha da China que separava as coisas-em-si dos homens-entre-si operava de fato no sentido de esconder as estranhas, indizíveis, monstruosas trocas que aconteciam em suas inumeráveis falhas.

Escreve o autor:

"O ponto essencial desta Constituição moderna é tornar invisível, impensável, irrepresentável o trabalho de mediação que produz os híbridos. Mas esse trabalho foi algum dia interrompido? Não, porque o mundo moderno pararia imediatamente de funcionar, uma vez que, como qualquer outro coletivo, ele vive da mistura. A beleza do dispositivo aparece assim em plena luz. A constituição moderna permite, ao contrário, a proliferação sem precedentes de híbridos, cuja existência - e mesmo a possibilidade - ela nega" (Latour, 1991, p. 53). 
A diferença, pois, entre sociedades modernas e não-modernas está apenas na escala em que cada uma é capaz de mobilizar as coisas através da produção de híbridos. No mundo não-ocidental ou não-moderno, a produção dos híbridos se veria limitada ou constrangida pelo fato de a ordem natural e a ordem social se corresponderem termo a termo, tornando impossível "mudar a ordem social sem mudar a ordem natural, e inversamente" (Latour, 1991, p. 62). Dito de outro modo, entre eles, a ordem natural seria sagrada.

Entre nós, a crença (pois se trata claramente de crença para Latour) na separação ontológica entre natureza e cultura permitiu a "recombinação de todos os monstros possíveis" (Latour, 1991, p. 63). E foi sua assustadora proliferação que teria feito ruir a própria constituição moderna, tornando visível o que ela ocultava:

\begin{abstract}
"Quando surgiam apenas algumas bombas de vácuo, ainda conseguíamos ao menos classificá-las ou no arquivo das leis naturais, ou no arquivo das representações políticas, mas agora que fomos invadidos por embriōes congelados, sistemas inteligentes, máquinas digitais, robôs munidos de sensores, milho híbrido (...) e que nenhuma dessas quimeras sente-se confortável nem do lado dos objetos, nem do lado dos sujcitos, nem no meio, é preciso fazer alguma coisa." (Latour, 1991, p. 72).
\end{abstract}

Mas, o que nos interessa aqui é apontar para a perturbadora contradição que uma leitura mais atenta do trabalho de Latour faz emergir. Para muitos, a esta altura ela já deve ter se tornado bem visível. De fato, sua análise se orienta e se estrutura a partir da própria constituição moderna que ele condena. Latour infinitas vezes chama a atenção para o seu caráter falseador, uma vez que separa objeto e sujeito, matéria e idéia etc. Porém, ao mesmo tempo, ele está nos dizendo que, "na realidade", existem híbridos, enquanto "no pensamento" persistem formas puras, essências. E eis que reencontramos, no próprio argumento do autor, o que julgávamos conjurado para sempre: a separação entre as coisas-em-si, em sua brutal realidade, e os homens-entre-si, perdidos em suas representações, suas ideologias, seu imaginário, seus símbolos. De um lado, a constituição moderna; de outro, os fenômenos empíricos.

Se Latour parece não conseguir se desvencilhar do princípio que, para ele, gera tantos males, talvez seja pelo fato de continuar profundamente comprometido com o próprio ethos da modernidade. Seu trabalho, como o de todos os modernos que ele critica, procura "desvelar-nos o real", "afastar falsos conceitos" para que possamos ver enfim a luz matinal da verdade. É 
um trabalho de denúncia em nome da verdade. Nada mais moderno...

Do nosso ponto de vista, este fato não tira nem o brilhantismo, nem a originalidade, nem o caráter profundamente instigante das idéias de Latour - apenas os limita. Weberianamente, talvez tivesse sido muito mais interessante se, ao invés de fundamentar sua análise em matters-of-fact, Latour pudesse mostrar, para além da riqueza analítica da perspectiva que desenvolve, o que a tornou historicamente possível. Dizer apenas que a constituiçăo moderna ruiu pela pressão insuportável de uma "realidade" que ela negava parece uma petição de princípio. Principalmente para alguém que, como Latour, sabe muito bem que a "realidade" só "fala" através de seus delegados ou representantes, no caso os cientistas. É Latour que faz falar os híbridos. É ele quem os mobiliza contra a perspectiva crítica mantida por inúmeros cientistas sociais, filósofos e antropólogos. E talvez um pouco da história desse pensamento crítico possa iluminar as condições de possibilidade das propostas de Latour.

Ora, a crítica social contra a qual Latour se insurge avolumou-se sobretudo a partir dos anos 60 , atacando duramente o reducionismo biologizante, o cientificismo e a própria transcendentalidade da natureza. Foi justamente através dela que as tecnociências começaram a ver seu prestígio social seriamente abalado, tornando-se mais prontamente nossos objetos, ou seja, assunto das ciências humanas e sociais. Pouco importa que isso tenha se dado pelo fato de a ciência não conseguir mais mobilizar as coisas como antigamente, ou pelo fato de um conjunto de incidentes (bomba atômica, talidomida, Tuskeege etc.) ter semeado dúvidas quanto à sua capacidade de saber exatamente o que estava mobilizando e como o estava fazendo, de prever todas as possíveis conseqüências de suas "invenções". O que interessa ressaltar aqui é que a Antropologia social, sempre dilacerada entre a constituição moderna e a não-moderna ou romântica, espraiou-se espetacularmente nas ondas da crítica social e cultural que se avolumou a partir dos anos 60. Nesse processo produziu ela própria seus "híbridos" acadêmicos, antropólogos profissionais enviados para as "fronteiras" disciplinares, como é o caso do próprio Bruno Latour, que não o deixa de assumir explicitamente (Latour, 1991, p. 10).

Ao que parece, esses antropólogos estão agora voltando para relatar o que viram por lá. Latour vem de muito "longe". Enviado como tantos outros ultimamente para o mundo das coisas, para vê-las sob a ótica da sociedade, ele parece ter passado progressivamente a ver a sociedade pela ótica das coisas. E, como outros antropólogos fizeram com índios, camponeses, ho- 
mossexuais e mulheres, ele, de certo modo, reclama para elas o direito de "cidadania". E, independentemente de concordar ou não com todas as suas formulações ou a perspectiva mais geral que ele adota, aí reside, para nós, o aspecto mais interessante da trajetória que seu pensamento descreve.

\section{Referências Bibliográficas}

BOURDIEU, P. Les rites comme actes d'institution. Actes de la Recherche en Sciences Sociales, n. 43, junho 1982.

CARRARA, S. Entre cientistas e bruxos: ensaio sobre os dilemas e perspectivas da análise antropológica da doença. In: ALVES, P. C.; MINAYO, M. C. S. Saúde e doença: Um olhar antropológico. Rio de Janeiro: Fiocruz, 1994.

DURKHEIM, E. Les formes élémentaires de la vie religieuse. Paris: P.U.F., 1990 [1912].

GEERTZ, C. The way we think now. In: Local knowledge. New York: Basic Books, 1983.

MAUSS, M. Esquisse d'une théorie générale de la magie. In:

Sociologie et Anthropologie. Paris: P.U.F., 1991 [1902-3].

. Divisions et proportions des divisions de la sociologie. In:

Oeuvres. Paris: Minuit, 1969 [1927].

. Essai sur le don - forme et raison de l'échange dans les siciétés archaîques. In: . Sociologie et Anthropologie. Paris: P.U.F., 1991 [1923-24].

LATOUR, B. Laboratory life - the construction of scientific facts. Los Angeles: Sage, 1978. . Les microbes, guerre et paix. Paris: Métalié, 1984.

Science in action. Cambridge: Harvard University Press, 1989. Nous n'avons jamais été modernes - essai d'anthropologie symetrique. Paris: La Découverte, 1991. 


\section{NOTAS}

1 Comunicaçāo apresentada à IV Jornada Latino-Americana de Estudos Sociais da Ciência e Tecnologia (ESOCITE), mesa-redonda "Antropologia da Ciência e da Tecnologia". Unicamp, Campinas, de 23 a $26 / 10 / 2000$.

2 Professor adjunto de Departamento de Políticas e Instituiçōes de Saúde do Instituto de Medicina Social da UERJ.

3 Publicado em 1994, pela Editora 34, com o lítulo Jamais fomos modernos - ensaio de antropologia simétrica.

4 Ver, nesse sentido, Durkheim (1990 [1912]).

5 Para consideraçōes mais alentadas sobre o caráter simbólico da atividade científica, ver Carrara (1994).

6 Bruno Latour é professor no Centre de Sociologie de L'Innovation da École Nationale Supérieure des Mines de Paris. 